\title{
Design and Simulation of the Control System for Inverte-fed Permanent Magnet Synchronous Motor Drive
}

\author{
Ramana Pilla $^{1}$, Killari Santukumari ${ }^{2}$, K.B.Madhu Sahu ${ }^{3}$ \\ ${ }^{1,2}$ Department of Electrical and Electronics Engineering, GMR Institute of Technology, Rajam, AP, India-532127 \\ ${ }^{3}$ Aditya Institute of Technology and Management, Tekkali, AP, India-532201
}

\begin{tabular}{l} 
Article Info \\
\hline Article history: \\
Received May 6, 2018 \\
Revised Jun 7, 2018 \\
Accepted Sep 22, 2018 \\
\hline Keywords: \\
Non-linear controller \\
Non-linear full order observer \\
State feedback controller \\
PMSM
\end{tabular}

PMSM

\begin{abstract}
Development in the field of power electronics, cost effective DSP's and microprocessors have opened a new era in the design and implementation of modern control strategies for variable speed drives. This paper presents the design of a control system which includes a non-linear controller and observer for inverter fed Permanent Magnet Synchronous Motor (PMSM) Drive. The entire design is carried out by designing of Speed Controller, Non-linear Controller (NLC), State Feedback Controller (SFC) and Non-linear Full order Observer (NFO). The proposed control scheme is extensively simulated under various conditions using MATLAB/Simulink, which shows better performance under all operating conditions for variable speed PMSM drive.
\end{abstract}

Copyright $(2018$ Institute of Advanced Engineering and Science. All rights reserved.

\section{Corresponding Author:}

Ramana Pilla,

Department of Electrical and Electronics Engineering,

GMR Institute of Technology,

GMR Nagar, Rajam, Andhra Pradesh, India-532127.

Email: ramana.pilla@gmrit.org, pramana.gmrit@gmail.com

\section{INTRODUCTION}

In high power applications, PMSM drives are widely used in order to get trailblazing performance such as fast dynamic response, high power density, high efficiency [1], [2] and wide speed range. Due to these advantages PMSM is widely used in industries, robotics, rolling mills, hybrid electric vehicles [2] etc. Though it has many advantages, the major problem is cost of PMSM is very high for high power applications [3], [4]. So, in order to overcome this problem, PMSM is not practically constructed but its blocks are brought together and prototype is made using simulation. The simulation of PMSM involves selecting of all the components to obtain steady state and dynamic performance as if the machine is actually constructed. In simulation, PMSM is considered with damper windings [5] in order to damp out oscillations under transient conditions.

In general, when PMSM is operated at different frequencies either in open loop or closed loop operation it may be stable. But, when it is driven at low frequencies there may be a problem of abrupt stopping, pull-out from its operation, undesirable performance etc. At this condition, the PMSM cannot be operated under wider range of speeds satisfactorily. Even though when it is designed in closed loop, the linear techniques are not directly applicable since the model of PMSM inherently non-linear.

For the above mentioned problem, PMSM requires a stable closed loop control system [6] which may operate at any speed without losing stability under any conditions. So, in this paper, a closed loop control system is designed including non-linear controller [7], non-linear observer [8], [9] and state feedback controller. In the design process, the model of PMSM [2], [3] along with its parameters is used instead of real motor. So to represent the parameters of the machine, mathematical model [2], [3], [10] is required. Similarly to find out the performance of PMSM, a non-linear mathematical model is applied but, the conventional linear 
techniques cannot be applied directly in this situation. To overcome this drawback exact feedback linearization [11], [12] is applied using d-q transformation, whereas, the non-linear feedback law taken care of decoupling as well as compensate the influence of emf. In order to develop a high performance control system, accurate information of machine states is important. For this purpose observers [8], [9] are used. These observers are defined as an algorithm producing observer signals, from the sensed signals with the knowledge of control system which makes the system less costly, accurate and more reliable. The four states of PMSM such as stator and damper winding currents are estimated using NFO, which are feedback to the SFC [13].

\section{MODELLING OF PMSM}

The modeling equations of PMSM with damper windings on rotor reference frame using Park's transformation [2], [3], [12] are:

$$
\begin{aligned}
& v_{q s}=r_{a} i_{q s}+l_{q s} p i_{q s}+l_{a q} p i_{q r}+\omega_{r} l_{d s} i_{d s}+\omega_{r} l_{a d} i_{d r} \\
& v_{d s}=r_{a} i_{d s}+l_{d s} p i_{d s}+l_{a d} p i_{d r}-\omega_{r} l_{q s} i_{q s}-\omega_{r} l_{a q} i_{q r} \\
& v_{d r}=r_{d r} i_{d r}+l_{d r} p i_{d r}+l_{a d} p i_{d s} \\
& v_{q r}=r_{q r} i_{q r}+l_{q r} p i_{q r}+l_{a q} p i_{q s}
\end{aligned}
$$

The electrical torque developed by PMSM is:

$$
T_{e}=\frac{3}{2} \times \frac{P}{2}\left[\left(l_{a d}-l_{a q}\right) i_{d s} i_{q s}+l_{a d} i_{q s} i_{d r}-l_{a q} i_{q r} i_{d s}\right]
$$

The torque balance equation for PMSM by taking no. of poles $\mathrm{P}=4$ is:

$$
p \omega_{r}=\frac{2}{J}\left[T_{e}-T_{1}-\frac{B \omega_{r}}{2}\right]
$$

Hence, by using system and torque equations one can model PMSM.

\section{CONTROL SYSTEM DESIGN}

The block diagram of the proposed control system [6], [13] is shown in Figure 1 and it is of a conventional two loop structure. Out of the two loops, current loop is the inner loop and speed loop is the outer loop for an SPWM voltage source inverter fed PMSM drive. The reference torque is produced in speed loop, with PI controller as speed controller, by which reference currents $\mathrm{i}_{\mathrm{qs}} *$ and $\mathrm{i}_{\mathrm{ds}} *$ are computed for a desired torque angle $(\delta)$ and internal angle $(\psi)$. With the knowledge of these two angles, there is a chance of operating the motor under any power factor over lagging to leading along with unity.

For the inner current loop, a NLC is designed in order to cancel out the system non-linearity employing exact feedback linearization [7], [11], [12]. To achieve zero steady state error an IOE is used for reference current specification. Also, a linear state feedback control law is involved for stability based on pole placement technique. To implement SFC, the information of all states is required in order to control the dynamic behaviour of the system. Therefore, there is a requirement of estimating the inaccessible currents of damper windings by using a NFO [8]. 


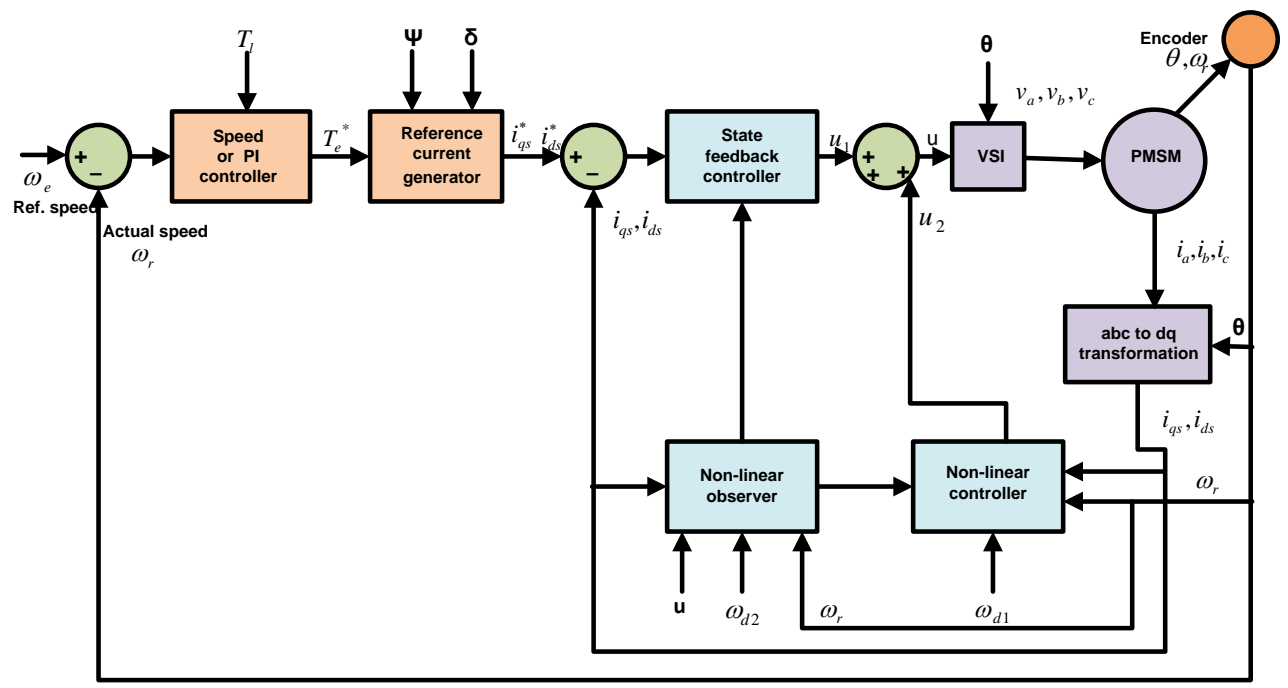

Figure 1. Proposed control system and its block diagram

\subsection{Design of a Speed Controller}

The design of the speed controller is as follows:

The motor torque balance equation in terms of speed, for no. of poles $\mathrm{P}=4$ is

$$
p \omega_{r}=\frac{2}{J}\left[T_{e}-T_{1}-\frac{\beta \omega_{r}}{2}\right]
$$

The speed controller equation is

$$
T_{e}^{*}=k_{p} e+k_{i} \int_{0}^{t} e d t
$$

Where, $\quad e=\left(\omega_{e}-\omega_{r}\right)$

Here, $k_{p}=$ proportional gain and $k_{i}=$ integral gain of the PI controller.

Substituting equations (8) and (9) in equation (7) and taking Laplace transform, we get,

$$
\left(s \omega_{r}-\omega_{r 0}\right)=\frac{2}{J}\left[\left(k_{p}+\frac{k_{i}}{s}\right)\left(\omega_{e}-\omega_{r}\right)-T_{l}-\left(\frac{\beta}{2}\right) \omega_{r}\right]
$$

For $T_{l}=0 \& \omega_{r 0}=\omega_{e}$ and the equation (10) becomes,

$$
\frac{\omega_{r}}{\omega_{e}}=\frac{\frac{2}{j}\left(k_{p}+\frac{k_{i}}{s}\right)+1}{s+\frac{\beta}{J}+\frac{2}{J}\left(k_{p}+\frac{k_{i}}{s}\right)}=\frac{\left(\frac{2}{J} k_{p}+1\right) s+\frac{2}{J} k_{i}}{s^{2}+\left(\frac{\beta}{J}+\frac{2}{J} k_{p}\right) s+\frac{2}{J} k_{i}}
$$

Now the characteristic equation becomes,

$$
s^{2}+\left(\frac{\beta}{J}+\frac{2}{J} k_{p}\right) s+\frac{2}{J} k_{i}=0
$$


The standard second order control system characteristic equation is:

$$
s^{2}+2 \xi \omega_{n} s+\omega_{n}^{2}=0
$$

On comparing equations (12) \& (13) and simplifying, will get,

$$
\begin{aligned}
& k_{i}=\frac{J}{2} \omega_{n}^{2} \\
& k_{p}=J \xi \omega_{n}-\frac{\beta}{2}
\end{aligned}
$$

Where, $\xi=$ damping ratio, and $\omega_{\mathrm{n}}=$ natural frequency of oscillations.

By selecting suitable values of $\xi$, $\omega_{\mathrm{n}}$, machine parameters $\mathrm{J}$ and $\beta$, the gain constants $\mathrm{k}_{\mathrm{p}}$ and $\mathrm{k}_{\mathrm{i}}$ are computed.

\subsection{Reference Currents Generation}

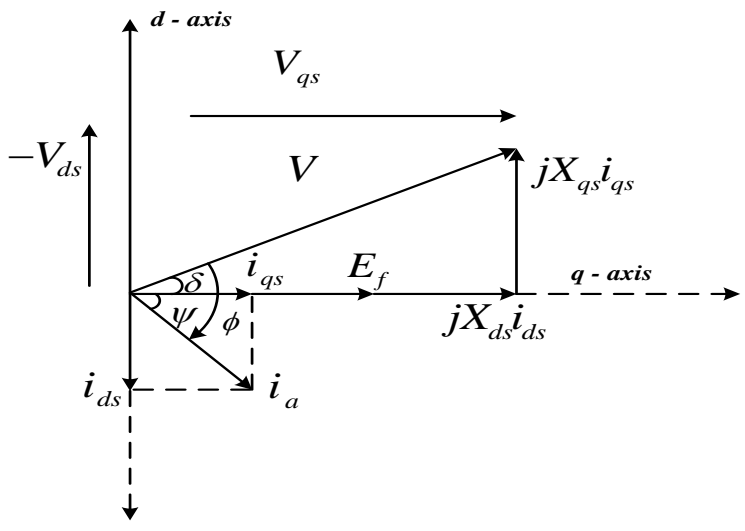

Figure 2. Phasor diagram

a) Taking torque angle, $\delta$ as a specification

$$
\begin{aligned}
& i_{d s}^{*}=\frac{-q_{2} \pm \sqrt{q_{2}^{2}-4 q_{1} q_{3}}}{2 q_{1}} \\
& i_{q s}^{*}=\frac{T_{e}^{*}}{3\left(l_{a d}-l_{a q}\right) i_{d s}+\Psi}
\end{aligned}
$$

Where, $\quad q_{1}=3\left(l_{a d}-l_{a q}\right)\left(-r_{a}-\omega_{r} l_{d s} \tan \delta\right)$

$$
\begin{aligned}
& q_{2}=-3\left(l_{a d}-l_{a q}\right) \omega_{r} \Psi \tan \delta+3 \Psi\left(-r_{a}-\omega_{r} l_{d s} \tan \delta\right) \\
& q_{3}=-3 \Psi^{2} \omega_{r} \tan \delta-\left(r_{a} \tan \delta-\omega_{r} l_{q s}\right) T_{e}^{*}
\end{aligned}
$$

b) Taking internal angle, $\psi$ as a specification

$$
i_{q s}^{*}=\frac{-3 \Psi \pm \sqrt{9 \Psi^{2}+12 T_{e}^{*}\left(l_{a d}-l_{a q}\right) \tan \psi}}{6\left(l_{a d}-l_{a q}\right) \tan \psi}
$$




$$
i_{d s}^{*}=i_{q s}^{*} \tan \psi
$$

c) Field oriented (FO) control

$$
\begin{aligned}
& i_{d s}^{*}=0 \\
& i_{q s}^{*}=\frac{T_{e}^{*}}{3 \Psi}
\end{aligned}
$$

\subsection{Design of a Non-linear Controller}

In the mathematical model of PMSM, it is observed some part of system equation is a function of $\omega_{\mathrm{r}}$, and it varies with the operating point, due to this the system becomes non-linear and hence linear control techniques cannot be applied directly. In order to conquer this problem, a non-linear controller is designed in the inner current loop, to cancel out the system non-linearity employing exact feedback linearization [11], [12]. Now the electrical subsystem is expressed in system model as,

$$
\dot{x}=A x+B u
$$

Dividing $\mathrm{A}$ into $\mathrm{A}_{1}$ and $\mathrm{A}_{2}$, we have:

$$
\dot{x}=\left(A_{1}+\omega_{r} A_{2}\right) x+B u
$$

Thus, in equation (23) there is a proportional term to $\omega_{\mathrm{r}}$ in system matrix $\mathrm{A}$, so there is a need of feedback term, for the cancellation of the product depends on $\omega_{\mathrm{r}} \mathrm{x}$. To implement this, a feedback control law is chosen of the form,

$$
u=u_{1}+u_{2}
$$

Where, the non-linear input control vector is chosen as:

$$
u_{1}=\omega_{r} k_{1} x
$$

Where $\mathrm{k}_{1}=$ feedback gain matrix.

Substituting Equations (24) and (25) in equation (23)

$$
\dot{x}=\left(A_{1}+\omega_{r} A_{2}\right) x+B\left(u_{1}+u_{2}\right) \text { or } \dot{x}=A_{1} x+B u_{2}+\omega_{r}\left(A_{2}+B k_{1}\right) x
$$

To achieve exact cancelation of the non-linear term,

$$
A_{2}+B k_{1}=0 \Rightarrow A_{2}=-B k_{1}
$$

To satisfy equation (27), the matrix $\mathrm{k}_{1}$ is taken as:

$$
k_{1}=\left[\begin{array}{cccc}
0 & l_{d s} & 0 & l_{a d} \\
-l_{q s} & 0 & -l_{a q} & 0
\end{array}\right]
$$

Now, the equation (23) changes into standard linear form as,

$$
\dot{x}=A_{1} x+B u_{2}
$$

From the Equation (29), it is concluded that there is exact cancellation of the system non-linearity and also at all operating points, this linearization is valid. 


\subsection{State Feedback Controller}

In the inner current loop, a linear state feedback control law based on pole placement technique including integral of output error (IOE) is used.

$$
\dot{u}_{2}=v=K_{2} z=\left[\begin{array}{ll}
K_{b s} & K_{i s}
\end{array}\right]\left[\begin{array}{c}
\dot{x} \\
y-y_{r}
\end{array}\right]
$$

The IOE is integrating and modified as,

$$
u_{2}=\int_{0}^{t} v d t=K_{b s} x+K_{i s} \int_{0}^{t}\left(y-y_{r}\right) d t
$$

The SFC requires all the states information to be fed back. But, in PMSM some of the states are inaccessible for availability of feedback. For this purpose an NFO [8], [9] is designed.

\subsection{Design of Non-linear Full order Observer}

Development of a high performance controller-observer needs an accurate estimation of machine states. In PMSM, four states such as stator and damper winding currents have to be estimated to implement SFC. For this purpose, an NFO [8], [9] is designed and the procedure is as follows:

The system equations of PMSM in state space form

$$
\begin{aligned}
& \dot{x}=A x+B u \\
& y=C x \\
& \zeta=L x
\end{aligned}
$$

In matrix form it can be written as,

$$
\begin{aligned}
& {\left[\begin{array}{l}
y \\
\hat{\zeta}
\end{array}\right]=\left[\begin{array}{l}
C \\
L
\end{array}\right] x} \\
& \hat{x}=\left[\begin{array}{l}
C \\
L
\end{array}\right]^{-1}\left[\begin{array}{l}
y \\
\hat{\zeta}
\end{array}\right]
\end{aligned}
$$

An observer is a dynamical system can be represented by,

$$
\dot{\hat{\zeta}}=D \hat{\zeta}+G u+F y
$$

And the value of $\mathrm{F}$ is chosen as,

$$
F=F_{1}+\left(\omega_{r}-\omega_{d}\right) F_{2}
$$

Where $F_{2}=L\left(A_{y}^{-1}\right) F_{3}$ and $F_{3}=\left[\begin{array}{cc}0 & -l_{d s} \\ l_{q s} & 0 \\ 0 & 0 \\ 0 & 0\end{array}\right]$

The error in the estimate of $\zeta$ can be obtained as: 
$\dot{\tilde{\zeta}}=\dot{\hat{\zeta}}-\dot{\zeta}=D \hat{\zeta}+(G-L B) u+\left[F_{1} C+\left(\omega_{r}-\omega_{d 2}\right) F_{2} C-L\left(A_{1}+\omega_{d 2} A_{2}\right)-\left(\omega_{r}-\omega_{d 2}\right) L A_{2}\right] x$

For the condition of asymptotically accurate estimate of $\zeta$

$$
\begin{aligned}
& \dot{\tilde{\zeta}} \rightarrow 0 \text { or } \hat{\zeta} \rightarrow \zeta, \text { as } t \rightarrow \infty \\
& \dot{\tilde{\zeta}}=D(\hat{\zeta}-\zeta)-\left[L A_{d}-F_{1} C-D L+\left(\omega_{r}-\omega_{d 2}\right) L\left(A_{2}-A_{y}^{-1} F_{3} C\right)\right] x
\end{aligned}
$$

For the error estimation of $\zeta, \dot{\tilde{\zeta}}=\dot{\hat{\zeta}}-\dot{\zeta}$ to decay,

(i) $L\left(A_{2}-A_{y}^{-1} F_{3} C\right)=0$

(ii) $L A_{d}-F_{1} C-D L=0$

(iii)D should be a stable matrix with the restriction that

$$
\left\{\lambda_{i}\right\}_{D} \neq\left\{\lambda_{i}\right\}_{A}
$$

From the above conditions, the matrices $\mathrm{D}, \mathrm{L}$ and $\mathrm{F}_{1}$ values are selected as

$$
L=\left[\begin{array}{llll}
l_{11} & l_{12} & l_{13} & l_{14} \\
l_{21} & l_{22} & l_{23} & l_{24} \\
l_{31} & l_{32} & l_{33} & l_{34} \\
l_{41} & l_{42} & l_{43} & l_{44}
\end{array}\right], F_{1}=\left[\begin{array}{ll}
f_{11} & f_{12} \\
f_{21} & f_{22} \\
f_{31} & f_{32} \\
f_{41} & f_{42}
\end{array}\right], D=\left[\begin{array}{llll}
d_{11} & d_{12} & d_{13} & d_{14} \\
d_{21} & d_{22} & d_{23} & d_{24} \\
d_{31} & d_{32} & d_{33} & d_{34} \\
d_{41} & d_{42} & d_{43} & d_{44}
\end{array}\right]
$$

\section{RESULTS AND DISCUSSIONS}

a) Simulation results of the PMSM drive for a step change in speed corresponding to a frequency of $\mathrm{f}_{\mathrm{r}}=4 \mathrm{~Hz}$ to $10 \mathrm{~Hz}$ at a load torque of $2 \mathrm{~N}-\mathrm{m}$.

Figure 3 visibly shows that due to feedback linearization the transients are died out and the transient response is improved. Using NLC, it is observed that steady state values are obtained at faster rate and peak overshoots in the currents at initial period of time are reduced. The linear controller has a disadvantage that for wider change in speed reference it is failed, but the designed controller is working continuously. The simulation results in Figure 4 shows that, there is a perfect estimation of $d-q$ axes damper winding currents $\left(i_{\mathrm{qr}} \& \mathrm{i}_{\mathrm{dr}}\right)$ i.e. these currents are settled at zero under steady sate. But in transient period, some values of currents are existed due to damper windings. This concludes that the observer converges at very faster rate i.e. the currents are oscillatory under transient state and almost nearer to the actual states. Coming to the stator estimated states, that is, $d-q$ axes stator currents $\left(i_{\mathrm{qs}} \& i_{\mathrm{ds}}\right)$, they are almost equal to the actual states. Figure 5 shows the simulation results of the proposed drive system for a step change in speed corresponding to a frequency of $\mathrm{f}_{\mathrm{r}}=4 \mathrm{~Hz}$ to $10 \mathrm{~Hz}$ at a load torque of $2 \mathrm{~N}-\mathrm{m}$ for different values of $\psi$ resulting in variation of p.f. from lagging to leading including unity \& u.p.f. occurs at $\psi=-19.1^{0}$. Above Figure 6 shows the simulation results of the proposed drive system for different values of $\delta$ resulting in variation of p.f. from lagging to leading including unity \& u.p.f occurs at $\delta=8.735^{\circ}$. Figure 7 shows the simulation results of the proposed drive system for the field oriented case, which is achieved by making $\psi=0^{0}$ resulting in $i_{d s}=0 \mathrm{~A}$. Under FOC the motor always operates at lagging p.f. and $\phi=\delta=10.8^{0}$. From the simulation results as shown in Figures 8 to 10 , the settling time is increased due to variation in load torque $\mathrm{T}_{1}=5 \mathrm{Nm}$ to $9 \mathrm{Nm}$ at constant speed corresponding to a frequency of $\mathrm{f}_{\mathrm{r}}=10 \mathrm{~Hz}$ and after some transients the system is coming to normal operation. 

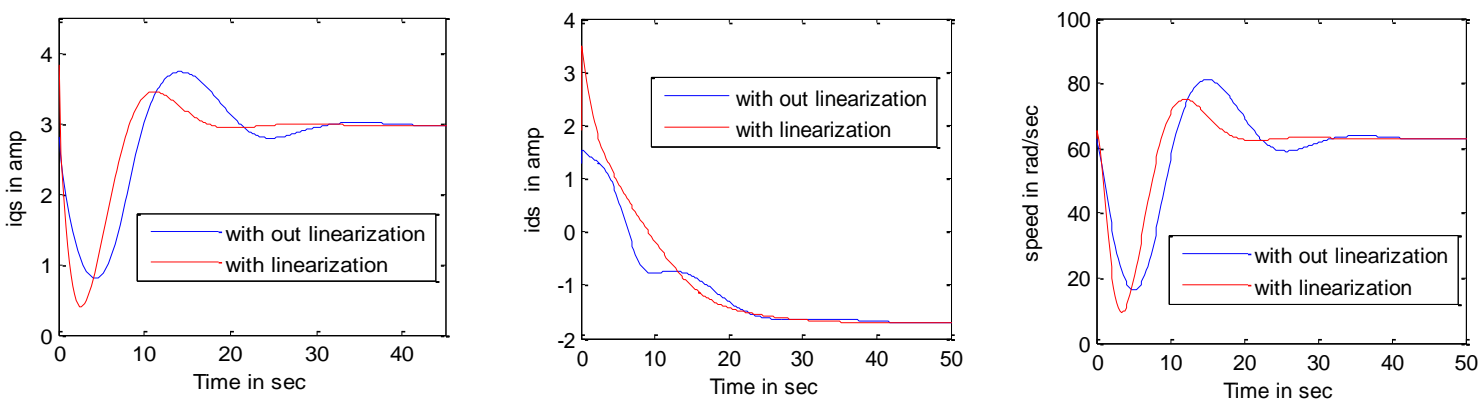

Figure 3. Simulation results of the SFC with and without feedback linearization
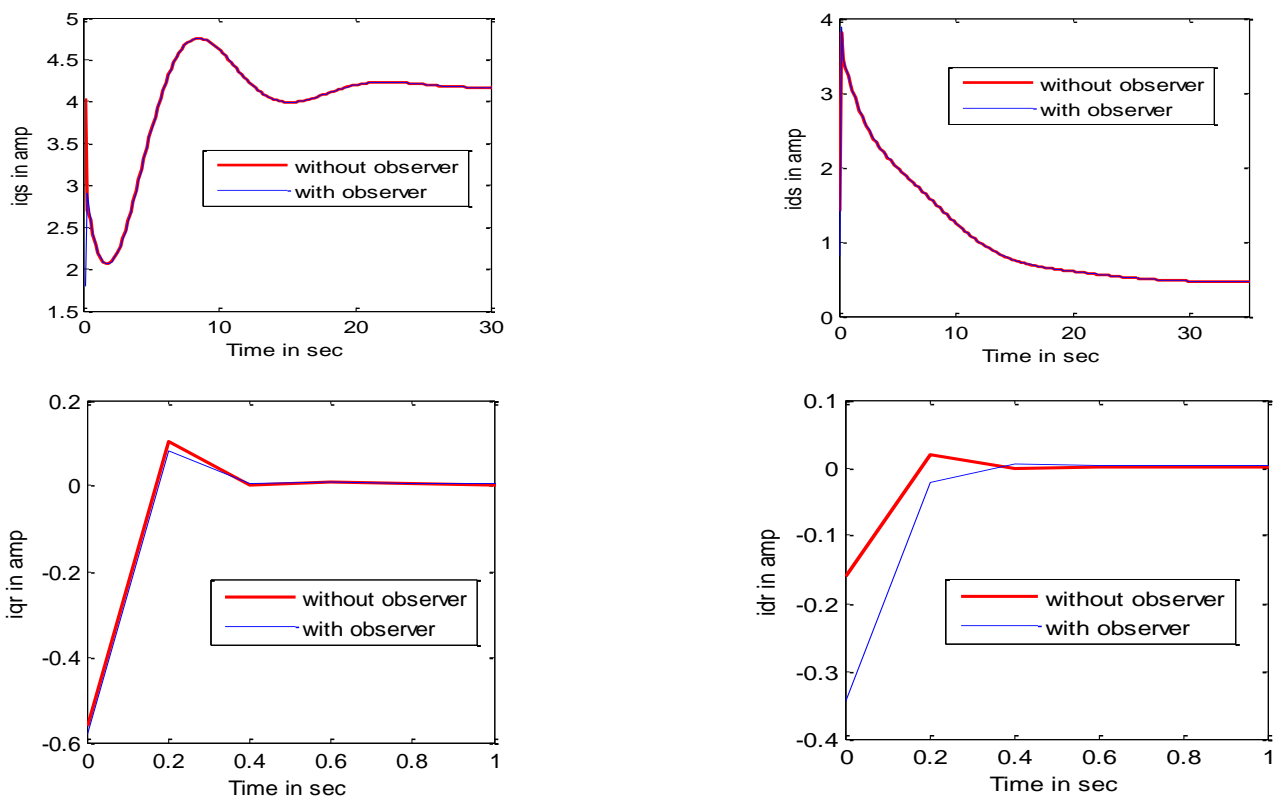

Figure 4. Simulation results of NFO with actual and estimated states
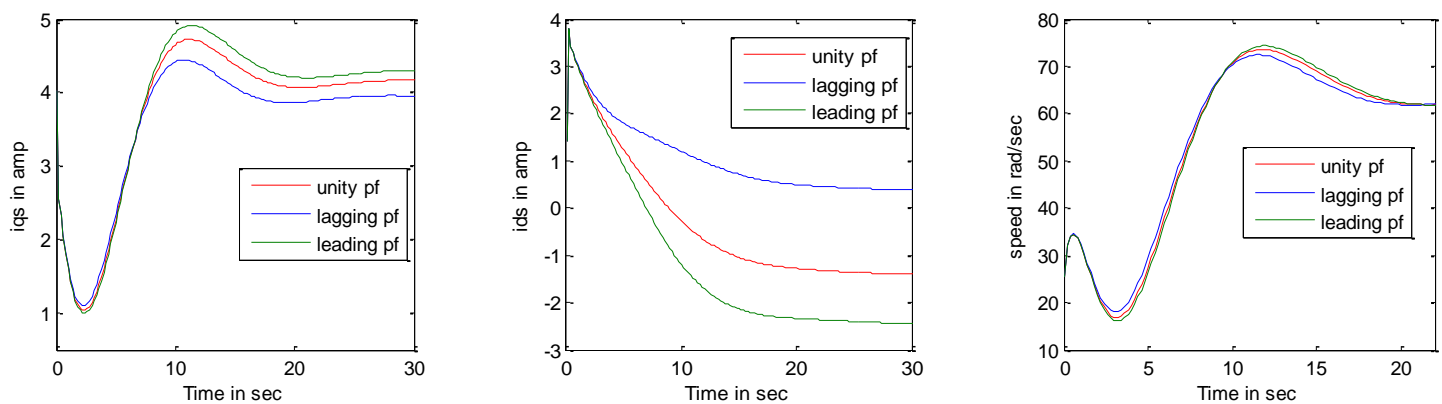

Figure 5. Simulation results of the proposed control system for different values of (a) $\psi=-19.1^{0}$ (u.p.f) (b) $\psi=5^{0}$ (lagging p.f) (c) $\psi=-30^{0}$ (leading p.f) 

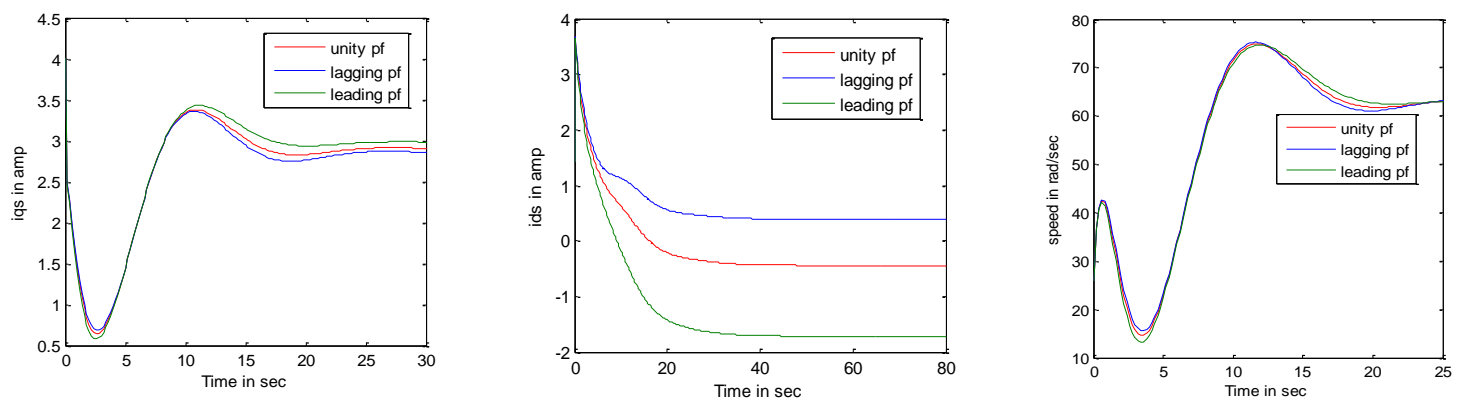

Figure 6. Simulation results of the proposed control system for different values of (a) $\delta=8.735^{0}$ (u.p.f) (b) $\delta=5^{0}$ (lagging p.f) (c) $\delta=15^{0}$ (leading p.f)
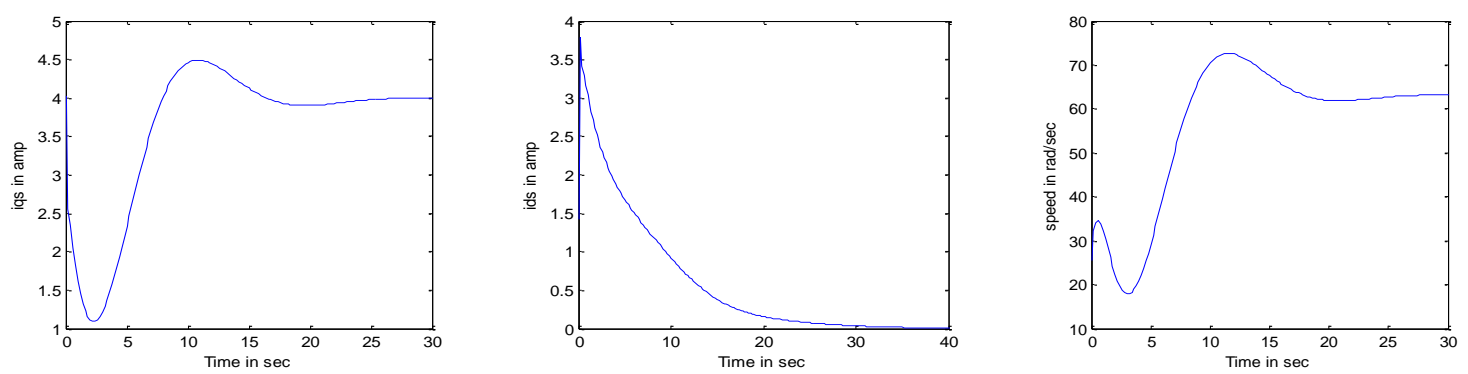

Figure 7. Simulation results of the proposed control system for FOC $\left(\psi=0^{0}\right)$

b) Simulation results of the PMSM drive for a step change in load torque of $\mathrm{T}_{1}=5 \mathrm{Nm}$ to $9 \mathrm{Nm}$ at constant speed corresponding to a frequency of $\mathrm{f}_{\mathrm{r}}=10 \mathrm{~Hz}$.
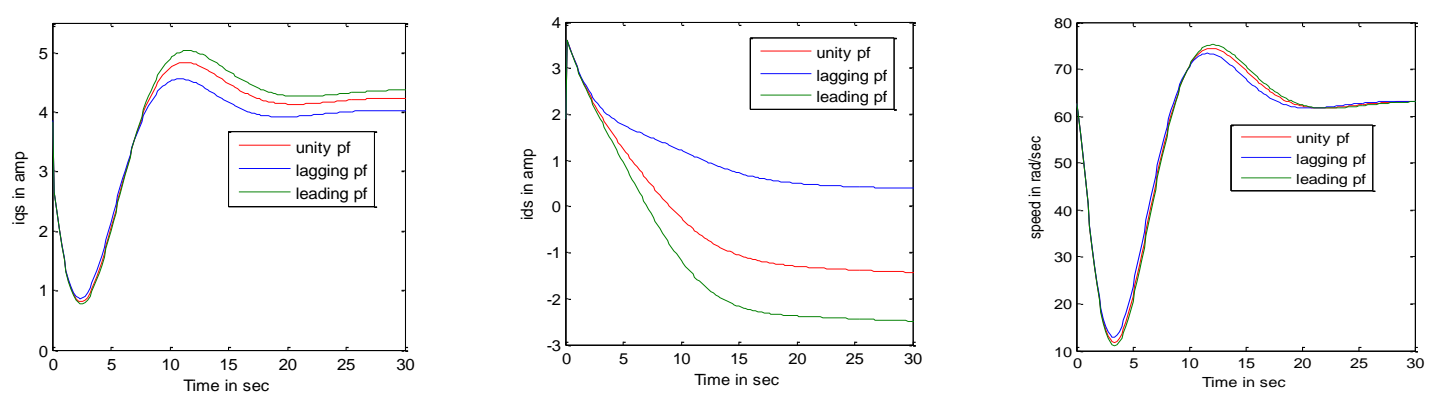

Figure 8. Simulation results of the proposed control system for different values of (a) $\psi=-19.1^{0}$ (u.p.f) (b) $\psi=5^{0}$ (lagging p.f) (c) $\psi=-30^{0}$ (leading p.f)
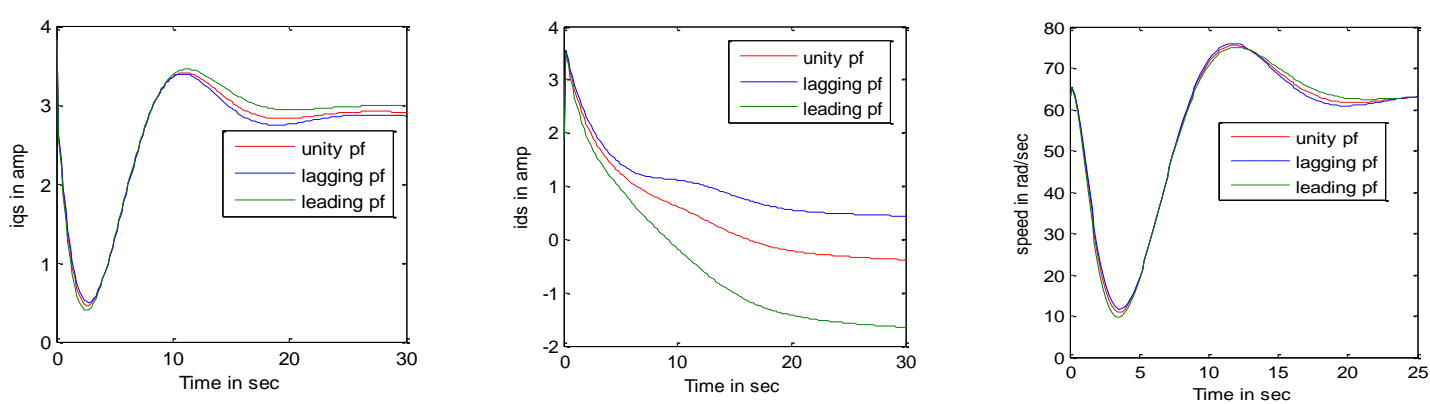

Figure 9. Simulation results of the proposed control system for different values of (a) $\delta=8.735^{\circ}$ (u.p.f) (b) $\delta=5^{0}$ (lagging p.f) (c) $\delta=15^{\circ}$ (leading p.f) 

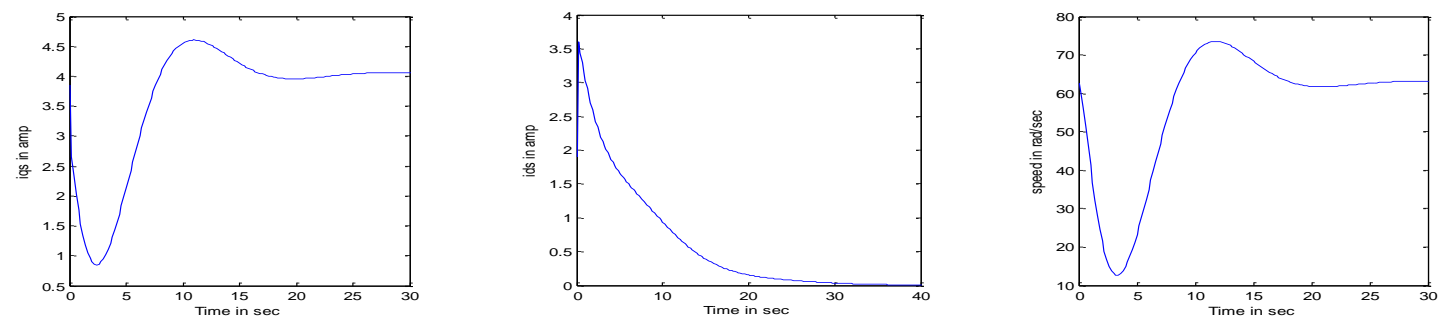

Figure 10. Simulation results of the proposed control system for FOC $\left(\psi=0^{0}\right)$

\section{CONCLUSION}

The proposed drive system is extensively simulated under all operating conditions including the p.f over lagging to leading along with unity. By selecting proper values of $\xi$ and $\omega_{\mathrm{n}}$ of system, the speed controller is designed to achieve desired speed response. An NLC is designed in the inner current loop based on exact feedback linearization to make the system model as linear. An SFC is also designed for enhancing the stability of system using pole placement technique comprising of linear state feedback control law. For implementation of SFC all the system states are required, to control the dynamic behaviour of the system. Therefore, an NFO is designed for estimates the system states. The proposed control system has been evaluated through extensive simulation using MATLAB, which gives better performance under all operating conditions.

\section{REFERENCES}

[1] G. Kron, "Generalized theory of electrical machinery," Transactions of the American Institute of Electrical Engineers, vol.49, no.2, pp.666-683, 1930.

[2] Pragasen Pillay and Ramu Krishnan., "Modelling of Permanent Magnet Motor Drives," IEEE Transactions on Industrial Electronics, vol. 55, no.4, pp.537-541, 1988.

[3] Pragasen Pillay and Ramu Krishnan, "Modelling, simulation and analysis of Permanent magnet motor drives, PartI: The Permanent Magnet Synchronous Motor Drive," IEEE Transactions on Industry Applications, vol. 25, no.2, pp. 265-273, 1989.

[4] Yusnida Ahmad Tarmizi et al., "Review and Comparison of Sensorless Techniques to Estimate the Position and Speed of PMSM," International Journal of Power Electronics and Drive System, vol. 8, no. 3, pp. 1062-1069, September 2017.

[5] A.B.Proca, A. Keyhani, A.E.L. Antably, W. Lu and Min Dai, "Analytical Model for Permanent Magnet Motors with Surface mounted Magnets," IEEE Transactions on Energy Conversion, vol. 18, no.3, pp.386-391, 2003.

[6] K. Alice Mary, A. Patra, N. K. De and S. Sengupta, "Design and Implementation of the Control System for an Inverter-fed Synchronous Motor Drive," IEEE Transactions on Control Systems Technology, vol. 10, no.6, pp. 853859, 2002.

[7] P. Ramana, K. Alice Mary and M. Surya Kalavathi, "State Feedback Linearization of a Non-linear Permanent magnet Synchronous motor drive," Indonesian Journal of Electrical Engineering and Computer science," vol. 1, no.3, pp. 234-542, 2016.

[8] P Ramana, K Alice Mary, M Surya Kalavathi and J Hareesh Kumar, "Design of a Non-linear Reduced and Full order Observers for an Inverter Fed Permanent Magnet Synchronous Motor Drive," Indian Journal of Science and Technology, vol. 9, no.9, pp.01-08, 2016.

[9] P. Brandstetter, P. Rech and P. Simonik, "Sensorless Control of Permanent Magnet Synchronous Motor Using Luenberger Observer," PIERS Proceedings, pp.424-428, 2010.

[10] R. Aziz, G.J. Atkinson and S. Salimin, "Thermal Modelling for Permanent Magnet Synchronous Machine (PMSM)," International Journal of Power Electronics and Drive System, vol. 8, no. 4, pp.1903-1912, December 2017.

[11] S.Izad and M. Ghanbari, "Speed Control of Permanent Magnet Synchronous Motor using Feedback Linearization Method," Indian Journal of Fundamental and Applied Life Sciences, vol. 5, no.S 1 , pp. 3293-3298, 2015.

[12] G.Liu and C. Zhang, "LQR Control of Permanent Magnet Synchronous Motor Based on Exact State Feedback Linearization," International Review on Electrical Engineering, vol. 8, no.2, pp.626-632, 2013.

[13] Chiranjit Sain, Atanu Banerjee, Pabitra Kumar Biswas, "Comparative Performance Study for Closed Loop Operation of an Adjustable Speed Permanent Magnet Synchronous Motor Drive with Different Controllers," International Journal of Power Electronics and Drive System, vol. 7, no. 4, pp. 1085-1099, December 2016.

\section{Appendix-A: Machine Ratings and parameters of PMSM}

Rated voltage $=400 \mathrm{~V}$, Rated current $=2.17 \mathrm{~A}$, Rated speed $=1500 \mathrm{rpm}$, No. of poles $=4$, Power rating $=1.2 \mathrm{~kW}, 0.8$ p.f, $\quad \mathrm{ra}=6.1 \Omega, \quad \mathrm{rdr}=16 \Omega, \quad \mathrm{rqr}=4.167 \Omega, \quad \mathrm{ldr}=0.14454 \mathrm{H}, \quad \mathrm{lqr}=0.14 \mathrm{H}, \quad l l=0.016393 \mathrm{H}, \quad \mathrm{lad}=0.06228 \mathrm{H}, \quad \mathrm{laq}=0.03975 \mathrm{H}$, $\mathrm{J}=0.048 \mathrm{~kg} \cdot \mathrm{m} 2, \beta=0.0048 \mathrm{~N}-\mathrm{m} / \mathrm{rad} / \mathrm{sec}$. 